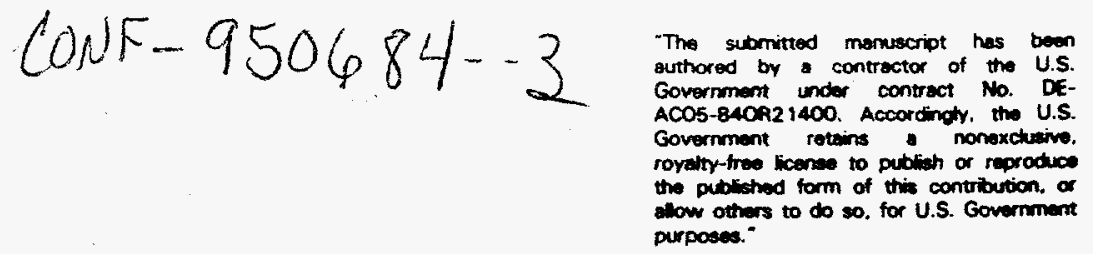

\title{
DIFFRACTION TECHNIQUES IN ENGINEERING APPLICATIONS
}

\author{
Residual Stress User Center \\ High Temperature Materials Laboratory \\ Oak Ridge National Laboratory \\ Oak Ridge, TN 37831 USA
}

K.J. Kozaczek, C.R. Hubbard, T.R. Watkins, X-L. Wang, and S. Spooner

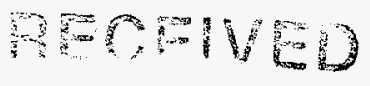

FEB 058993

Keywords: $x$-ray diffraction, neutron diffraction, residual stress, strain, texture. OSTI

\begin{abstract}
Diffraction techniques applied to crystalline materials provide quantitative information about the crystallographic structure and mechanical condition of the material. Those two characteristics influence the chemical, physical, and mechanical properties of a component. A concerted application of $x$-ray and neutron diffraction allows one to comprehensively study the bulk and subsurface variations of such material characteristics as crystallographic texture, residual stress, and cold work. The Residual Stress User Center at the Oak Ridge National Laboratory offers academic and industrial researchers both neutron and $\mathrm{x}$-ray diffraction capabilities. Recent examples of the application of work related to thin film, metal. ceramic and composite material technologies are presented.
\end{abstract}

\section{X-ray and Neutron Diffraction Characterization of Materials}

Material manufacturing processes, especially those involving large plastic deformations or phase transformations often introduce residual stresses, preferred crystallographic orientation (texture) and a high density of lattice defects.

The residual stresses affect the properties of the material and often are detrimental. They potentially can cause distortion of the product, initiate fracture, alter the tensile strength and fatigue life, and degrade the stress corrosion resistance. Such stresses can exist at different dimensions of a material (a) within crystalline grains at the level of lattice defects, (b) at a scale of many micrometers involving several grains or, (c) at a millimeter to centimeter scale encompassing variations over the entire structure. Microstresses at the scale of many micrometers are the key to toughening in composite materials. The residual stresses distributed on a macroscopic scale usually cause most of the degradation in engineering performance. Therefore, the distribution and magnitude of macro residual stresses in the final product are usually an important factor in manufacturing process optimization or component life prediction.

$\mathrm{X}$-ray and neutron diffraction techniques are widely used for nondestructive measurement of applied and residual stresses. The advances in detector and X-ray generation technology made the field, in situ measurements of residual and applied stresses feasible. Research reactors are open to academic and industrial researchers providing for an easy and relatively inexpensive access to neutron sources.

All diffraction methods measure the interplanar spacings in a phase in the material. The interplanar spacings serve as strain gages. Stresses are calculated from measured strains using diffraction elastic constants which are calculated theoretically or measured experimentally. Diffraction elastic constants depend strongly on the elastic anisotropy of a material and the degree of preferred crystallographic orientation (texture) within a particular component. For textured alloys, porous ceramics and composites, diffraction elastic constants can only be determined experimentally. X-ray and neutron diffraction are complementary techniques with respect to the volume and location of the portion of the material being investigated. Table 1 shows the probing depth (thickness of material that attenuates an incoming beam by factor of 2 ) for $\mathrm{x}$-rays and neutrons for some engineering materials. Note the change from $\mu \mathrm{m}$ to $\mathrm{mm}$ when going from $\mathrm{x}$-rays to neutrons. 
Table 1. Radiation penetration depths for selected engineering materials.

\begin{tabular}{|l|l|l|l|}
\hline Material & MoK $\alpha[\mu \mathrm{m}]$ & CuK $\alpha[\mu \mathrm{m}]$ & Neutrons $[\mathrm{mm}]$ \\
\hline Iron & 23 & 3 & 5.8 \\
\hline Aluminum & 484 & 52 & 66.4 \\
\hline Silicon & 444 & 49 & 59.1 \\
\hline $\mathrm{Al}_{2} \mathrm{Q}_{3}$ & 497 & 55 & 23.9 \\
\hline $\mathrm{TiO}_{2}$ & 110 & 13 & 11.2 \\
\hline $\mathrm{ZrO}_{2}$ & 90 & 11 & 15.5 \\
\hline Lead & 4 & 3 & 18.6 \\
\hline
\end{tabular}

Standard XRD (Bragg-Brentano geometry) measures residual strain in the vicinity of the surface and is capable of mapping sub-surface stress gradients with spatial resolution less than 50 microns. High sub-surface stress gradients are generated by finishing operations such as machining, grinding. carburizing, nitriding etc. If stress gradients at depths larger than the penetration depth are to be investigated then local material removal (etching, electropolishing) combined with corrections for stress relief must be applied. Figure 1 shows the sub-surface residual stress and retained austenite distribution measured by $\mathbf{x}$-ray diffraction and layer removal technique. The stresses developed as a result of the carburizing (quenching and martensitic transformation) of 5120 steel cylinders. These stresses affect the dimensional stability of the component. The transformation of retained austenite to martensite during service, and residual stress redistribution associated with the transformation, affect the component performance e.g., rolling cycle fatigue life.

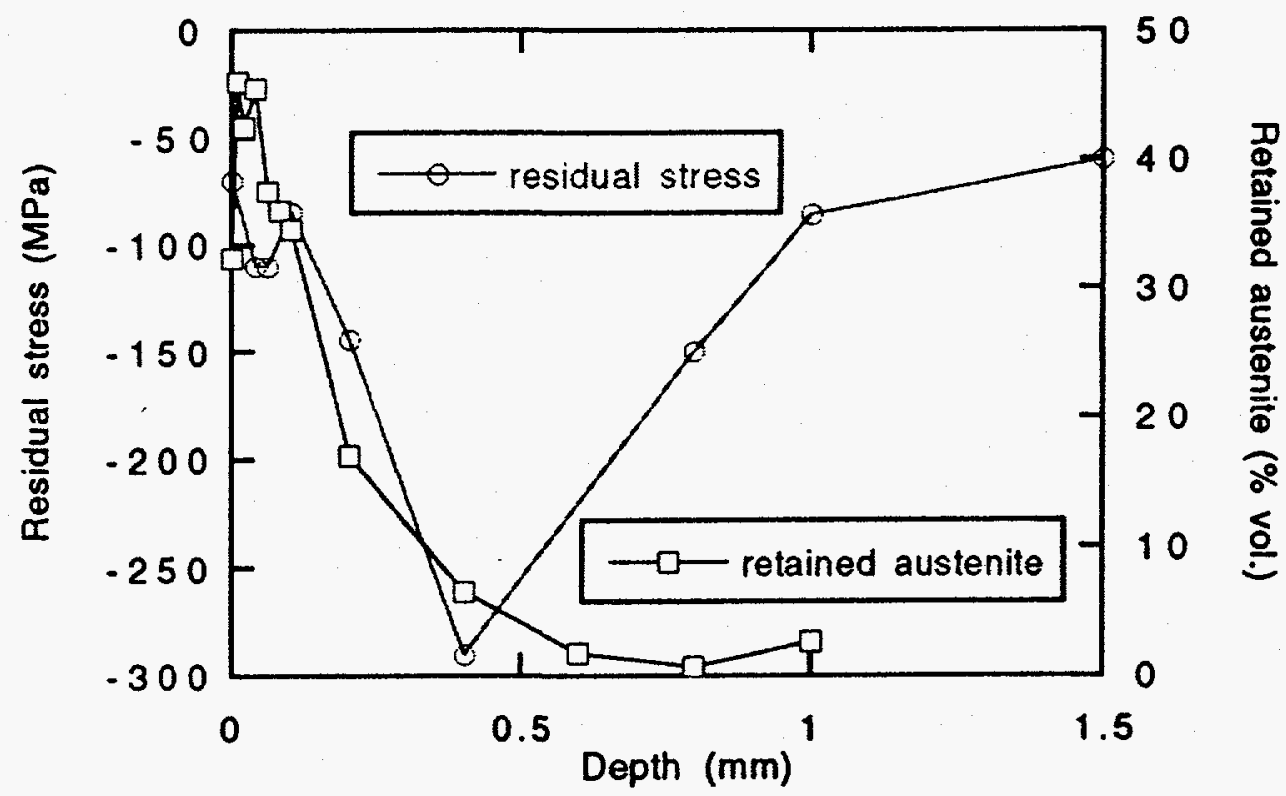

Figure 1. Residual stress and retained austenite depth profiles at the flat surface of a carburized 5120 disk ( $35 \mathrm{~mm}$ in diameter).

The importance of residual stresses in thin film technology has forced new techniques to evolve which allow one to measure stress in films with the thickness of hundreds of angstroms. The grazing incident x-ray diffraction technique (GIXD) is capable of measuring stress gradients with depth increments of tens of angstroms. In brittle materials such as ceramics, surface stresses are important since surface flaws often control failure. Grazing incidence $\mathrm{x}$-ray diffraction with parallel beam optics 
was used to obtain residual stress information as a function of penetration depth in machined $\mathrm{Al}_{2} \mathrm{O}_{3}[1]$. A plate of $\mathrm{Al}_{2} \mathrm{O}_{3}$ was ground with a 120 grit wheel and then with a 320 grit wheel (abrasive size: 125 and $35 \mu \mathrm{m}$, respectively). AS shown in Figure 2, steep stress gradients were found to exist in the near surtace region $(<4 \mu \mathrm{m})$ both parallel to $\left(\sigma_{11}\right)$ and perpendicular to $\left(\sigma_{22}\right)$ the machining direction. A compressive $-600 \mathrm{MPa}$ maximum was observed with GIXD while conventional diffraction methods, which average stresses over larger penetration depths, revealed only $-20 \mathrm{MPa}$ on this same sample. The 1/e penetration depth. tau, is the depth at which $63 \%$ of the scattered intensity comes from above that depth [2]. Thus, the information content is an absorption-weighted integral of response at each incremental depth beginning at the surface. The stresses were calculated using the 0 integral method [3] assuming the strain normal to the sample surface was zero. GLXD provides useful information about stress gradients arising from machining or coating processes.

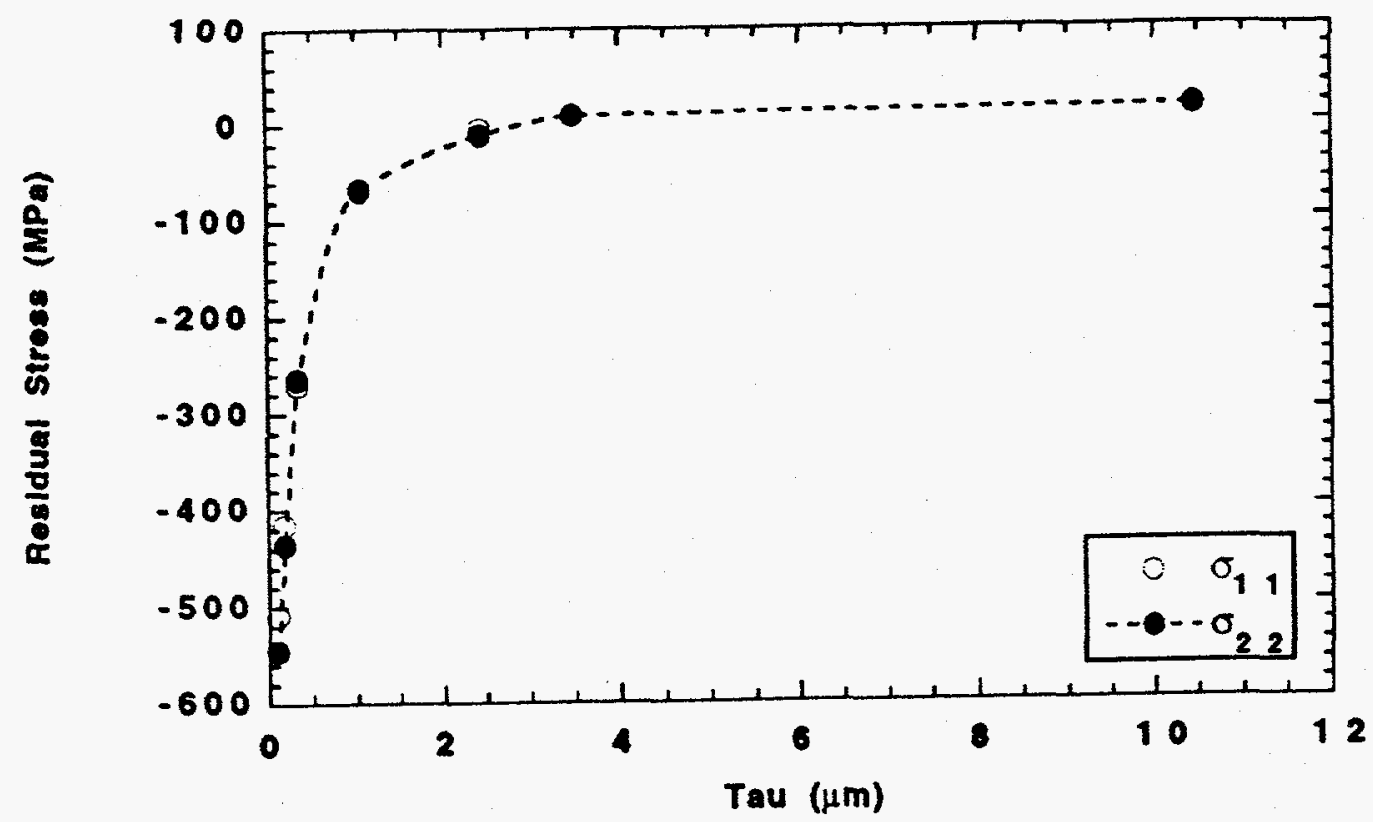

Figure 2. Residual stress in machined $\mathrm{Al}_{2} \mathrm{O}_{3}$ as a function of 1/e penetration depth. tau.

Neutron diffraction (ND) is capable of measuring the residual strains throughout the volume of a specimen (i.e.. mapping of stresses in thick-walled components) with a spatial resolution as high as $1 \mathrm{~mm}^{3}$. This is important when considering manufacturing processes in which large volumes of material undergo a deformation (e.g.. autofrettage), phase transformation (e.g., martensitic transformation), or temperature gradients. Joining processes of similar materials (such as welding) or dissimilar materials (such as welding or brazing) introduce residual stress states varying throughout the component thickness. Heat treating processes, including thermal stress relief, cause a redistribution of residual stresses in the whole volume of material. Neutron diffraction provides for both global and local measurements through the controllable sampling volume. Efforts to decrease the sampling volume and to understand edge effects have resulted in a smooth transition between surface $\mathrm{x}$-ray measurements and sub-surface neutron measurements. The capability of using neutron diffraction in the subsurface regions is essential while studying residual stresses in ceramic coatings or dissimilar metal claddings. Substantial cold-cracking occurs during cooling of $\mathrm{FeAl}$ overlay (potential material for corrosion resistant cladding) on a ferritic steel substrate (Fig. 3a) and is attributed to $\mathrm{Eigh}$ residual stresses which develop due to temperature gradients and the thermal expansion mismatch. The residual stresses were mapped with a sampling volume of $1 \times 1 \times 1 \mathrm{~mm}^{3}$ in the overlay and $2 \times 2 \times 2 \mathrm{~mm}^{3}$ in the steel substrate. Fig $3 \mathrm{~b}$ shows high, close to the yield strength. tensile residual stresses in the FeAl overlay which are responsible for the cold-cracking. The large 
standard deviation for the FeAl data is caused by the large grain size $(0.2 \mathrm{~mm})$ of the overlay material.

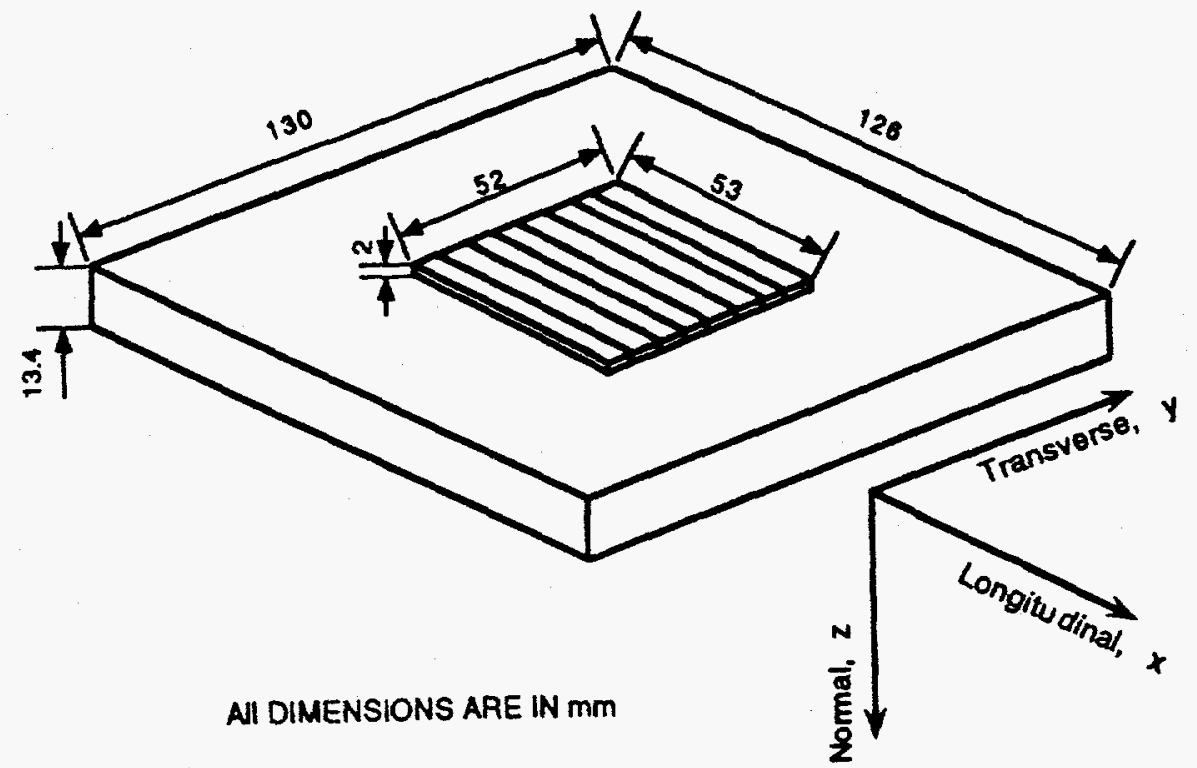

(a)

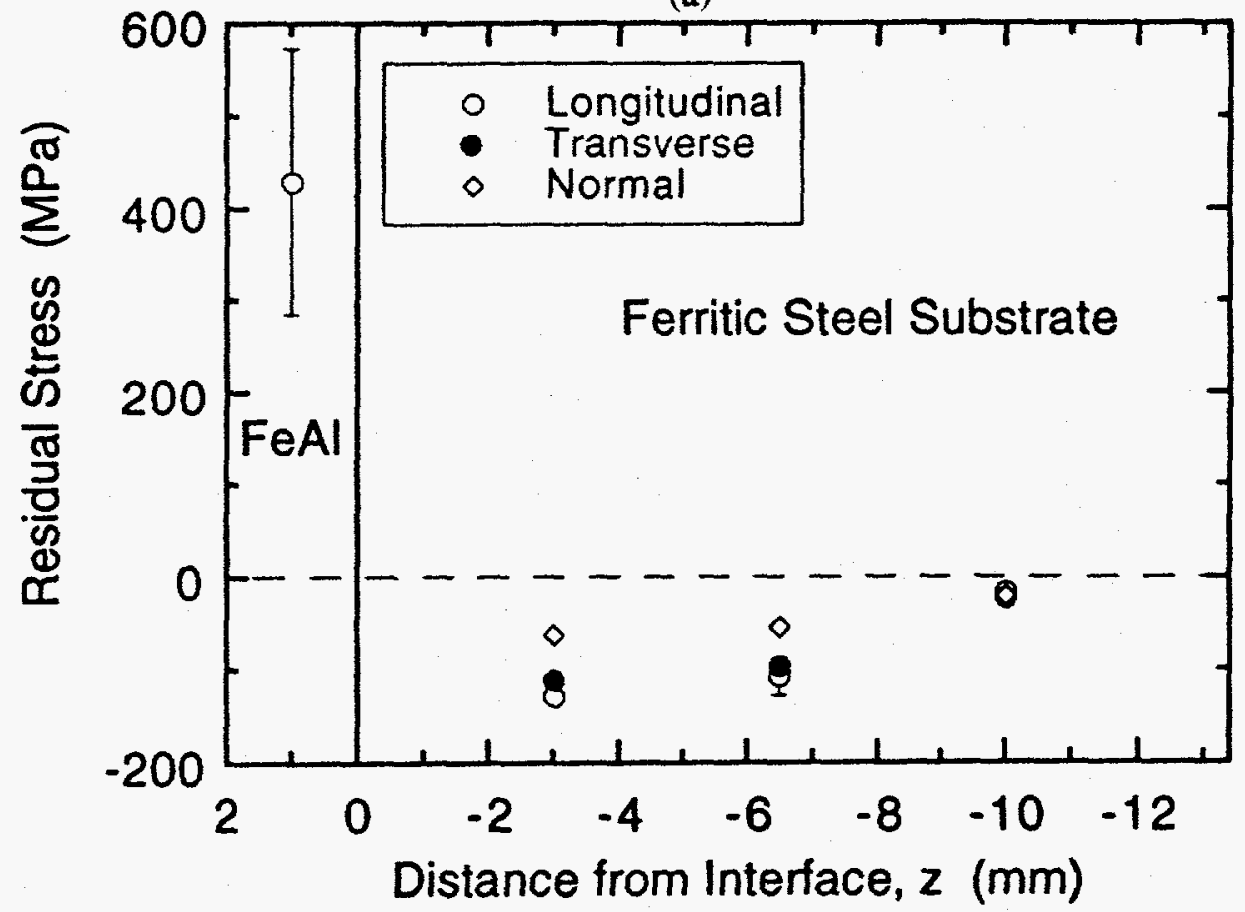

(b)

Figure 3. FeAl overlay on a $\mathrm{Cr}$-1Mo ferritic steel substrate (a). Residual stresses in the FeAl weld overlay specimen (b). Data in the ferritic steel substrate are for locations at the center of the weld overlay. Data in the FeAl weld represent an average over all locations where the longitudinal strain can be directly measured. For the substrate, the estimated standard deviations are plotted for one data point for clarity. After [4].

Neutron diffraction also enables studies of residual stresses and texture evolution at high temperatures (e.g., solidification, recrystallization) as well as to investigate, in situ, the material condition during mechanical deformation due to the fact that neutrons can penetrate through the environmental/mechanical chambers. Neutron diffraction is a useful tool to study multiphase systems such as metal alloys, intermetallics, and metal and ceramic matrix composites where high hydrostatic 
microstesses are present due to the thermo-elastic incompatibility between the phases. The microstress state in a zirconia-toughened alumina matrix composite was clearly revealed by high resolution neutron powder pattem analysis (Fig. 4). Lattice parameters for each of the phases were extracted from composite compositions of 10,20 and $40 \%$ vol. zirconia. Strains were obtained from lattice parameter shifts relative to the lattice parameters of pure strain-free powders. The stress state for zirconia was tensile and was compressive for alumina with a remarkably high tensile stress of $1 \mathrm{GPa}$ in $\mathrm{ZrO}_{2}$ for the $10 \%$ vol. zirconia composite. The net hydrostatic stress in the composite, obtained by balancing the contributions from each constituent phase, was shown to be effectively zero, which gives credence to the accuracy of the residual stress determinations in the two phases.

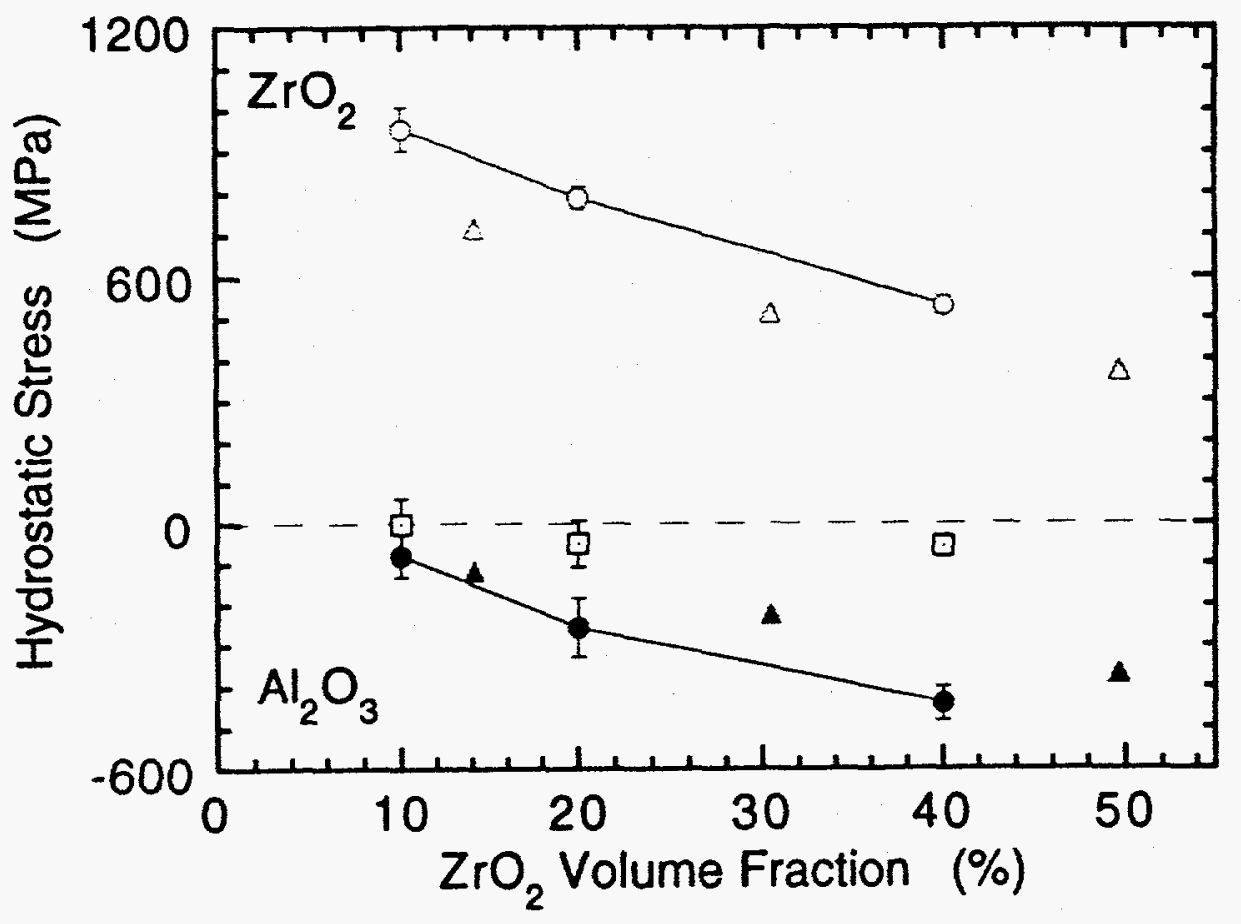

Figure 4. The hydrostatic stresses in $\mathrm{Al}_{2} \mathrm{O}_{3}-\mathrm{ZrO}_{2}$ composites as a function of the $\mathrm{ZrO}_{2}$ volume fraction. For comparison, the X-ray results of similar composites are also shown. The symbols are: open circles, $\mathrm{ZrO}_{2}\left(\mathrm{CeO}_{2}\right)$ (neutron measurements after [5]); solid circles. $\mathrm{Al}_{2} \mathrm{O}_{3}$ (neutron measurements after [5]); open squares, phase volume fraction weighted macrosresses; open triangles, $\mathrm{ZrO}_{2}\left(\mathrm{Y}_{2} \mathrm{O}_{3}\right)$ (X-ray measurements, after [6]); solid triangles, $\mathrm{Al}_{2} \mathrm{O}_{3}$ (X-ray measurements, after [6]).

Due to the anisotropy of most of the physical properties of single crystals and the fact that most material manufacturing processes (e.g., casting, forging, rolling, machining, depositing etc.) result in a preferred crystallographic orientation, the electric, magnetic, and mechanical properties of the final product are anisotropic. These anisotropic properties affect the manufacturability and performance of components. Quantitative texture analysis is a tool which provides the information necessary to control and optimize the manufacturing process and to predict specific physical properties. In recent years, significant progress has been made in developing experimental techniques for nondestructive texture analysis with $\mathrm{x}$-ray and neutron diffraction. Single pole or multiple pole density measurements combined with quantitative texture analysis emerged as a powerful tool for characterization and prediction of properties of polycrystalline materials ranging from thin films to heavy, metal products. Texture analysis was applied to understand the deviated crack paths in a compact tension specimen made of Weldalite (Al-Li-Cu alloy). The deviated crack paths (Fig. 5) were frequently observed in alloy 2095 plates in the T8 temper conditions which were welded with a 
AA2319 filler. The fatigue crack path consisted of three distinct regions (Fig. 5 b): an initial straight portion adjacent to the machined notch (intergranular decohesion rupture), a region deviated approximately $22^{\circ}$ to the weld centerline (transgranular shear), and a final rupture section perpendicular to the applied load. The $x$-ray diffraction texture measurements revealed a deformation texture of the base plates composed of $(112)<111>$ and $(110)<112>$ components (Fig. 5c). The crack deviation was caused by shear on $(111)<110>$ slip systems and its direction was accurately predicted from the texture data.

\section{Summary}

Diffraction techniques applied to crystalline materials provide quantitative information about the crystallographic structure and mechanical condition of the material. Those two characteristics influence the chemical, physical, and mechanical properties of a component. A concerted application of $x$-ray and neutron diffraction allows one to comprehensively study the subsurface and bulk variations of such material characteristics as crystallographic texture, residual stress, and cold work and provides the information necessary for manufacturing process optimization or component life prediction.

\section{Acknowledgments}

This project was sponsored by the U. S. Department of Energy, Assistant Secretary for Energy Efficiency and Renewable Energy. Otfice of Transportation Technologies, as part of the High Temperature Materials Laboratory User Program under contract DE-AC05-84OR21400. managed by Martin Marietta Energy Systems. Inc.

\section{References}

1. T. R. Watkins, K. J. Kozaczek, and C. R. Hubbard, "Depth Profiles of Residual Stresses in Machined $\mathrm{Al}_{2} \mathrm{O}_{3}$," in preparation.

2. B. Ballard, X. Zhu, P. Predecki, and D. Braski. "Depth Profiling of Residual Stresses by Asymmetric Grazing Incidence X-Ray Diffraction (GIXD)," pp. 1133-43 in Proceedings of the Fourth International Conference on Residual Stresses, Soc. Exp. Mech, 1994.

3. C. N. J. Wagner, B. Eigenmann. M. S. Boldrick, "The $\phi-$ Integral Method for X-Ray Residual Stress Measurements," pp.181-90, Advances in X-Ray Analysis, Vol. 31, ed. C. S. Barrett. J. V. Gilfrich, R. Jenkins, J. C. Russ, J. W. Richardson, Jr., P. K. Predecki. Plenum Press, New York, 1988.

4. X.-L. Wang. S. Spooner, C.R. Hubbard, P.J. Maziasz, G.M. Goodwin, Z. Feng, and T. Zacharia, "Residual Stress Distribution in FeAl Weld Overlay on Steel," pp. 109-114, Mat. Res. Soc. Symp. Proc., Vol. 364, MRS 1995.

5. X.-L. Wang, C.R. Hubbard, K.B. Alexander, and P.F. Becher, J.A. Fernandez-Baca, and S. Spooner, "Neutron Diffraction Measurements of the Residual Streses in Al2o3-ZrO2(ceO2) Ceramic Composites," pp. 1569-1575, J. Am.Ceram. Soc. 77(6), 1994.

6. K. Tanaka, M. Matsui, R. Shikata, and T. Nishikawa, "X-ray Measurement of Triaxial Residual Stress in Zirconia-Alumina Composite Ceramics," pp. 593-599, J. Soc. Mat. Sci. Japan, 41, 1992 (in Japanese). 


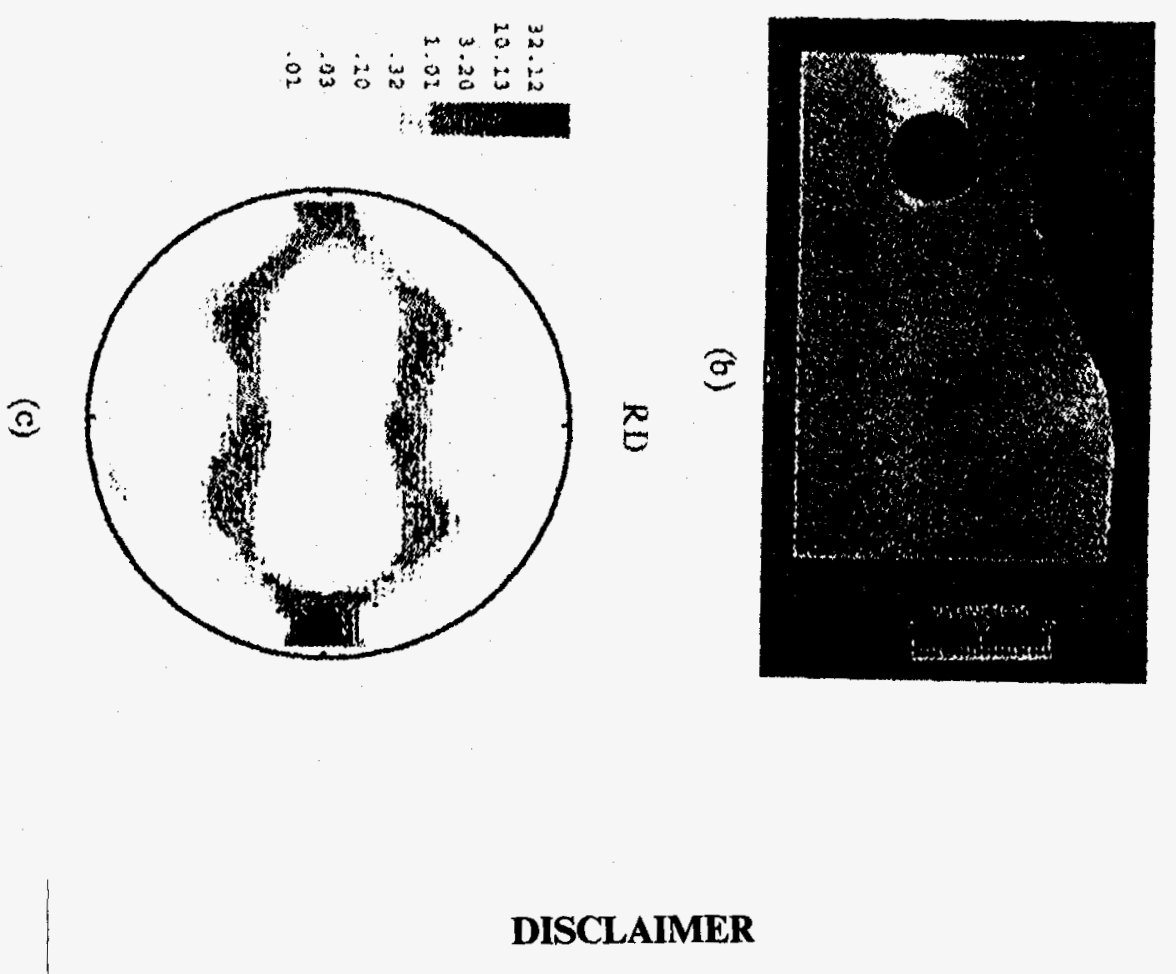

os is is

急

政

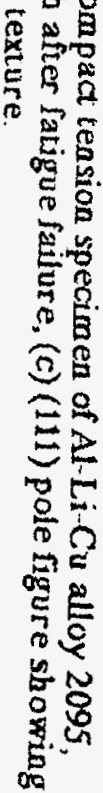

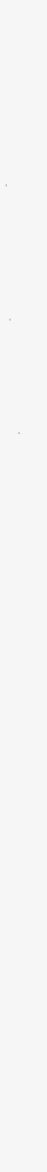

This report was prepared as an account of work sponsored by an agency of the United States Government. Neither the United States Government nor any agency thereof, nor any of their employees, makes any warranty, express or implied, or assumes any legal liability or responsibility for the accuracy, completeness, or usefulness of any information, apparatus, product, or process disclosed, or represents that its use would not infringe privately owned rights. Reference herein to any specific commercial product, process, or service by trade name, trademark, manufacturer, or otherwise does not necessarily constitute or imply its endorsement, recommendation, or favoring by the United States Government or any agency thereof. The views and opinions of authors expressed herein do not necessarily state or reflect those of the United States Government or any agency thereof. 